\title{
Daily work stress and relationship satisfaction: Detachment affects romantic couples' interactions quality
}

\author{
Anik Debrot, Sebastian Siegler, Petra L. Klumb, and Dominik Schoebi \\ University of Fribourg, Switzerland
}

Manuscript accepted for publication at the Journal of Happiness Studies doi: 10.1007/s10902-017-9922-6

\begin{abstract}
Author note
Anik Debrot, corresponding author, is now at the Institute of Psychology, University of Lausanne, Géopolis, 1015 Lausanne, Switzerland. Tel: +41 2169232 39, anik.debrot@unil.ch

Sebastian Siegler, Department of Psychology, University of Fribourg, Rue Faucigny 2, 1700 Fribourg, Switzerland.

Petra L.. Klumb, Department of Psychology, University of Fribourg, Rue Faucigny 2, 1700 Fribourg, Switzerland.

Dominik Schoebi, Department of Psychology, University of Fribourg, Rue Faucigny 2, 1700 Fribourg, Switzerland.
\end{abstract}

\section{Acknowledgments}

The first study was financed by grants PZ00P1_121616 and PZ00P1_136896 from the Swiss National Science Foundation to Dominik Schoebi, the second by a grant from Volkswagen foundation to Petra Klumb. We would like to thank Sylvia Böhme, Cristina Cretulescu, Christine Hennen, Kerstin Kaehlert, and Bianca Kusma for their diligent assistance in recruiting participants. Further thanks are due to Christiane Hoppmann and Melanie Staats. We are very grateful to Andrew Laughton for the reading and edits. 


\begin{abstract}
Psychologically detaching from work in the private setting is crucial to recover from work stress and promotes well-being. Moreover, broad evidence documents negative effects of stress on relationship quality. However, the interpersonal consequences of detachment have barely been studied. We seek to investigate, in daily life, whether and how detachment affects the interaction quality with the romantic partner. We propose that stress impedes detaching from work, and that detachment in turn, promotes individuals' ability to engage in positive interactions at home, which increases individual and relational well-being. In a first experience sampling study, involving 106 dual-earner couples with young children, detachment mediated the association between work stress and not only the stressed individual's, but also their partner's relationship quality. However, positive (affectionate) behaviors did not play a significant role in this process. In a second experience sampling study, involving 53 dual-earner couples with preschool children, detachment was associated with more affectionate interactions, which in turn, predicted lower actor, but not partner evening strain. These results suggest that detachment from work not only affects the working individual's, but also their close partner's the perception of their interactions, showing that detachment plays an important mediating role in the stress spillover and crossover process. This emphasizes the relevance of addressing interpersonal processes in the association between detachment and well-being.
\end{abstract}

Keywords: psychological detachment from work, relationship quality, affection, work stress, spillover and crossover, strain; romantic relationships; well-being. 


\section{Daily work stress and relationship satisfaction: Detachment affects romantic couples' interactions quality}

Navigating today's work environment is often challenging. An important ratio of workers experience negative health consequences from job stressors (American Psychological Association, 2016; Eurofound, 2015), particularly those who also must deal with family demands (i.e. dual-earner couples; Nohe, Meier, Sonntag, \& Michel, 2015). In the face of high demands, individual resources are consumed, and being able to conserve and recover these resources is challenging and yet essential for maintaining an adequate level of functioning (Hobfoll, 1989). Recovery from work is the replenishing of depleted resources when work stressors (e.g., high workload) are removed (Park \& Haun, 2016; Sonnentag \& Fritz, 2007). A whole line of research shows the importance of the ability to detach from work to maintain an adequate level of well-being and functioning (Sonnentag \& Fritz, 2015; Wendsche \& Lohmann, 2016). Nowadays, detaching might gain importance due to the increasing possibility to be constantly connected to one's job and the resulting blurred boundaries between work and private life (Allen, Cho, \& Meier, 2014).

Most research on psychological detachment from work (hereafter detachment) focuses on the individual. However, numerous research shows the critical role relational well-being for an optimal functioning (for a recent review see Robles, Slatcher, Trombello, \& McGinn, 2014), it thus seems essential to enlarge the perspective to the couple level. Several studies show how work stress negatively affects how people relate to close others (e.g. Randall \& Bodenmann, 2009.), both for the stressed individual (spillover) but also for their partner (crossover; Bakker \& Demerouti, 2013). In the present research, we seek to investigate the role of detachment in the spillover and crossover process of stress on relational well-being. Moreover, we examine how social resources (i.e. affection) can explain how detachment affects individual and relational well-being. 


\section{Stress and Relationship Quality}

Exposure to stressors and its resulting strain (i.e. the individual reaction to stressors) can harm romantic relationships. Partners of a couple experiencing higher stress levels report lower relationship quality (Randall \& Bodenmann, 2009; Westman, Vinokur, Hamilton, \& Roziner, 2004), both over extended periods of time (Neff \& Karney, 2007) and on a daily basis (Neff \& Karney, 2009; Timmons \& Margolin, 2017). The prolonged exposure to stress and its consequences for relationship quality ultimately increases the risk of marital dissolution (Neff \& Karney, 2004). Work stressors (i.e. stressful events or conditions encountered by one of the partners at work) count among the most frequent daily stressors (Almeida, 2005). According to the Spillover-Crossover Model (Bakker \& Demerouti, 2013), work-related experiences first spill over to the home domain, and then cross over to the partner through social interaction, and can thus affect relationship quality. These theoretical claims have been largely supported by empirical data; not only does stress affect the stressed individual's relationship quality (e.g. Neff \& Karney, 2009), but also the romantic partner's one (e.g. Carnes, 2017; Lavner \& Clark, 2017)

\section{Detachment in the Spillover and Crossover Process}

To better understand the pathways through which stressful work experiences can affect families, it is necessary to pinpoint the components underlying this process. Detachment from work during nonwork time means to disengage oneself psychologically from work in the private setting and is an essential recovery experience (Sonnentag \& Fritz, 2015). The Stressor-Detachment Model (Sonnentag, 2011) highlights the importance of detachment for the understanding of how stress spills over from work into the private setting. Job stressors often elicit a sustained negative activation and, in these conditions, disengaging from work when leaving the professional setting is harder, impeding or delaying recovery (Brosschot et al., 2006) and resulting in higher strain at home. A recent literature review 
documented vast empirical support for the mediating role of detachment in the stress spillover process of work stress on individual well-being into the private sphere (Sonnentag \& Fritz, 2015). This pattern has been demonstrated not only at the between-person level, indicating that people generally exposed to work stressors experience more strain at home, and a lack of detachment accounts for this association (e.g. Hahn \& Dormann, 2013), but also at the withinindividual level. On days when employees detach less, they experience higher strain in the private setting (e.g. Demerouti, Bakker, Sonnentag, \& Fullagar, 2012; Feuerhahn, Sonnentag, \& Woll, 2014), and detachment explains this association (ten Brummelhuis \& Bakker, 2012). Given the pervasive negative influence of work stress on relationship satisfaction (e.g. Randall \& Bodenmann, 2009), we hypothesize that detachment will mediate the daily association between work stress and own relationship quality at home (actor effect).

Stress also spreads beyond the stressed individual to family members (Bakker \& Demerouti, 2013; Carnes, 2017; Klumb, Völkle, \& Siegler, 2016). Thus, failing to detach from work should also affect the partner. However, very little research has addressed the interpersonal consequences of detachment. One cross-sectional study showed initial evidence that detachment can affect close relatives; partners of individuals who more effectively detach reported higher life satisfaction (Hahn \& Dormann, 2013). Moreover, the Stress-Divorce Model argues that stress affects relationship quality because stressed partners spend less time together (Randall \& Bodenmann, 2009). However, the interaction quality during that time should also matter. Indeed, individuals' negative work-related states predict more negative and less positive marital interactions, and this association is mediated by their lack of psychological availability (Danner-Vlaardingerbroek, Kluwer, van Steenbergen, and van der Lippe, 2013). Thus, in the present study, we predict that detachment will mediate the daily association between work stress and the partner's relationship quality (partner effect). 


\section{Does Detachment Set the Ground for More Affectionate Interactions?}

Social resources are an essential way to conserve one's own resources and/or to replenish them when depleted. They represent a broad meta-construct including "aspects of the commerce of supportive interactions, perceptions of receipt of support, and aspects of the self and whether it is viewed as supported" (Hobfoll, 2002, p.309). Affection is a particularly important social resource and is characteristic of close relationships, particularly of romantic ones (Floyd \& Riforgiate, 2008). According to the Affection Exchange Theory, affection is a feeling of fondness and intense positive regard for another person, or perceived from another person (Floyd, 2008). Affection is important for not only for individual well-being (Floyd, 2008; Debrot, Meuwly, Muise, Impett, \& Schoebi, 2017), but also for relational well-being as it is positively linked to relationship satisfaction and intimacy feelings (Floyd et al., 2005;

Debrot, Schoebi, Perrez, \& Horn, 2013). Moreover, it is associated not only with general and affective subjective well-being (e.g. Debrot et al., 2013), but also with reduced strain, both at the subjective and physiological level (e.g. Ditzen, Hoppmann, \& Klumb, 2008; Floyd, 2008).

When failing to detach, individuals maintain a higher level of arousal (Brosschot, 2010), impeding recovery from work strain, and thus individuals feel more fatigue and experience less energy and positive affect (Demerouti et al., 2012; Feuerhahn et al., 2014; Sonnentag \& Bayer, 2005). This may compromise their capacity to adequately interact with family members (Danner-Vlaardingerbroek et al., 2013). Thus, to be able to access social resources, letting work-related issues outside from the private sphere seems essential.

Accordingly, detachment is associated with less work-family conflict (Demsky, Ellis, \& Fritz, 2014). Moreover, detachment mediates the association between job demands and hostile behaviors at home (Meier \& Cho, 2016). Along with increasing negative behaviors, stress might also undermine positive family interactions. Furthermore, consistent evidence suggests that work stress increases social withdrawal at home (e.g. Schulz, Cowan, Pape 
Cowan, \& Brennan, 2004; for a review see Wang \& Repetti, 2012). Although withdrawal may be intended to prevent negative interactions, it also impedes positive ones. For example, mothers are less talkative and affectionate toward their children at the end of a more stressful work day (Repetti \& Wood, 1997). Moreover, a recent study indicated that daily work stress diminishes constructive reactions in couples' interactions (Unger, Sonnentag, Niessen, \& Kuonath, 2017). Therefore, we postulate that detachment will promote more affectionate daily experiences with the partner. Not only should individuals who detach more be better able to behave more affectionately, but this should allow them to also be more receptive, and thus perceive more affection in the interaction with their partner. This leads us to set the following processual hypothesis:

Hypothesis 1: Work stress affects both partner's daily relationship quality, and these actor and partner associations are mediated by the fact that, on higher stress days, people detach less from work, and as a consequence behave less affectionate with their partner, resulting in drops in daily relationship quality in both partners (double mediation, see Figure $1)$.

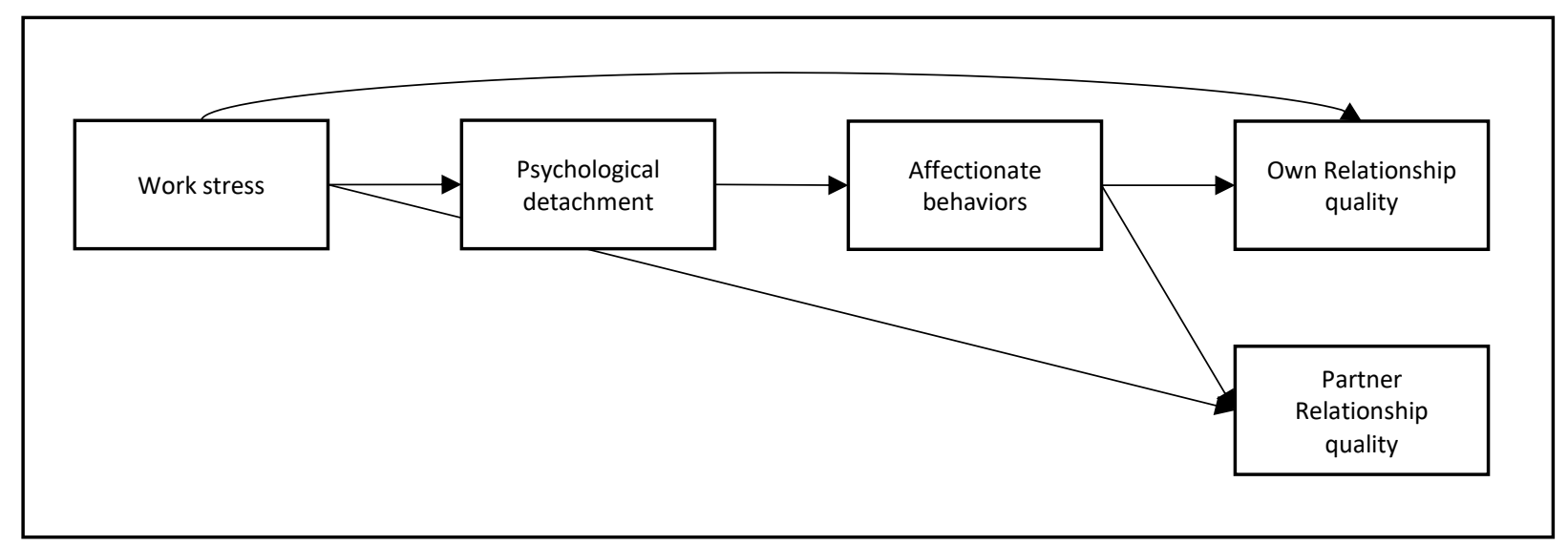

Figure 1: Conceptual model of Study 1 postulating that the association between work stress and both partners' daily relationship is mediated by detachment and affectionate behaviors. 
Additionally, given that detachment is robustly associated with lower individual strain (for a review, see Sonnentag \& Fritz, 2015), and the importance of affection for maintaining individual well-being, we postulate that affection would also explain why detachment affects individual strain. Strain is an individual's reaction (psychological, physiological, and behavioral) to a stressor, and a way to conceptualize and measure it is to assess the psychological negative activation (e.g. Côté, 2005). Here, we operationalize strain by measuring tense arousal, i.e. the subjective perception of a negative activation which has been shown to be distinct from the positive one (Schimmack \& Reisenzein, 2002).

An earlier study suggests that one's own detachment can also affect the partner's life satisfaction (Hahn \& Dormann, 2013). It is thus possible that one's detachment also affects the romantic partner's individual well-being on a daily basis. We therefore also tested the hypothesis that detachment would be associated with decreased daily strain levels in the partner, and that this partner effect is mediated by affectionate interactions (e.g., Debrot et al., 2013):

Hypothesis 2: Daily affectionate interpersonal interactions will mediate the association between daily detachment and actor and partner evening strain (see Figure 2).

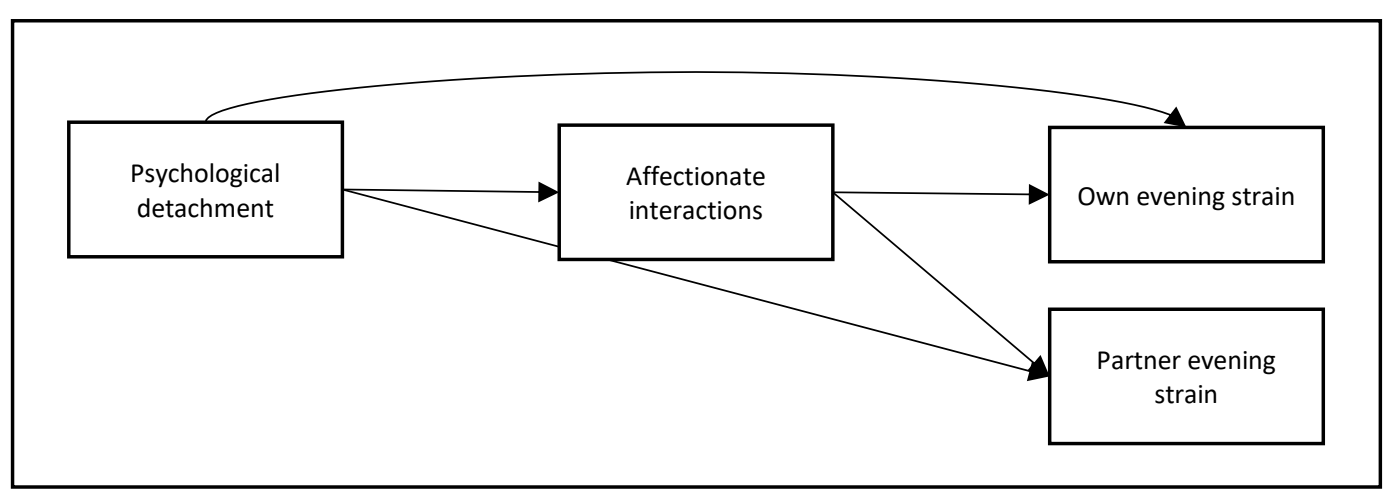

Figure 2: Conceptual model of Study 2 postulating that the association between detachment from work and both partners' evening strain is mediated by affectionate interactions. 


\section{The Current Research}

Our general aim is to examine the interpersonal consequences of detachment for individual and relational well-being in a population exposed to several demands. An experience sampling design has the distinct advantage to allow to investigate the day-to-day consequences of stress or detachment separately from general individual tendencies, and to promote the ecological validity and reliability of self-reports (Reis, 2012; Schwarz, 2012). Furthermore, a dyadic framework is ideal to investigate interpersonal processes. We therefore relied on data assessed in the daily life of two samples of dual-earner couples with children.

\section{Study 1}

In Study 1, in a sample of dual-earner parents we sought to investigate a double mediation model that allows to test our first processual hypothesis according to which work stress impedes detachment which in turn is associated with less affectionate behaviors toward the partner, resulting in a lower daily relationship quality (see Figure 1).

\section{Method}

\section{Participants and Procedure}

Participants were recruited by ads and flyers placed in childcare facilities, community centers, and common residential areas in the German speaking area of Switzerland. To participate, both partners had to (a) live together, (b), be professionally active for at least 12 hours per week, with a regular work schedule (excluding night shifts), and (c) have one or more children younger than eight years. Initially, 108 couples were recruited, but one couple was excluded because one spouse completed the diary reports on only three days, and another because both partners were women. The final sample had 106 couples.

The participants had an average age of 36.58 years $(S D=5.72)$. Relationship duration ranged from 2 years, 5 months to 12 years, 11 months $(M=10.2$ years, $S D=4.7)$. Most couples $(88.8 \%)$ were married. The sample was well-educated: $61.5 \%$ of the men and $56.6 \%$ 
of the women had a university degree, and $37.5 \%$ of the men and $43.3 \%$ of the women had a post-secondary school diploma. Most participants (38.3\%) had a monthly income between $\$ 3,000-\$ 6,000 \mathrm{USD}^{1} ; 33.5 \%$ earned more than $\$ 6,000$ USD per month. Men reported an average of 37.96 hours $(S D=5.87)$, and women 21.20 hours $(S D=6.73)$ of paid work per week. The couples had between one and five children $(M=1.67, S D=.82)$ who were a mean age of 4.54 years $(S D=4.17)$.

A research assistant first visited the couples in their homes. The participants also completed a set of paper and pencil questionnaires (not analyzed here, for more details, see Schoebi, Perrez, \& Bradbury, 2012). Participants received detailed instructions about the use of the handheld devices and reporting plan; they got an instruction manual and completed some practice exercises to ensure they understood the procedure.

During the 10-day assessment period, participants were instructed to complete a brief questionnaire ("diary”) at four specific times of the day, according to their individual schedule: (a) in the morning before starting work; (b) by the end of the workday (i.e., during the last hour of work or on the way home); (c) in the first 45 minutes after reunion with their partner, and (d) within the last hour before going to bed. The variables of interest for the present study were assessed either at the end of the workday (work stress) or in the evening (detachment, relationship quality and affection). Thus, only the "end-of-workday" and “evening” diaries were used here. Partners had one hour to complete each diary, and were instructed not to complete them retrospectively if forgotten, and not to discuss their responses with each other. On average, participants responded to $69.5 \%$ of the diaries ${ }^{2}$. After the procedure, each participant received the equivalent of \$50 USD.

\footnotetext{
1 The currency was Swiss francs, but to facilitate understanding, we indicated the amount in USD.

2 It has to be noted however, that the participants were given the possibility to keep the survey for four additional days, and the present dataset includes the 14 days for all participants. If we only consider the obligatory ten days, only $8 \%$ of the data was missing.
} 


\section{Daily Diary Measures}

Perceived stress at work. At the end of each work day, we asked whether the last hours were stressful for the participant on a scale ranging from $1=$ not at all, to $7=$ extremely. In the training session, participants were instructed to specifically consider work hours. The average stress level was $3.66(S D=.99)$, and did not differ between men $(M=3.65, S D=.95)$ and women $(M=3.67, S D=1.04), t_{(105)}=.21$, n.s.

Detachment from work. In the evening diary, participants were asked whether their job had occupied them during the evening on a scale ranging from $1=$ not at all, to $7=$ extremely. This indicator reflects the reverse of a central item of the Recovery Experience Questionnaire ${ }^{3}$ (“I don't think about work at all.”; Sonnentag \& Fritz, 2007), which has very high factor loading with the Detachment dimension of the latter. The item was thus reverse coded to reflect detachment from work. During the training session, we specified that the question referred to whether participants kept thinking, worrying, or actively dealing with work related issues even though they did not actually intend to work. On average, participants reported relatively high levels of detachment $(M=5.29, S D=1.06)$, and men's scores $(M=$ $5.23, S D=1.03)$ did not differ from women's scores $\left(M=5.35, S D=1.10 ; t_{(105)}=.83, \mathrm{n} . \mathrm{s}\right)$.

Relationship quality. In the evening diary, participants responded to the following items: Today, my relationship was: (a) as I like it, (b) somewhat difficult (reversed item), (c) distant, we lived past each other (reversed item), (d) harmonious. Items ranged from $1=$ not at all, to $7=$ extremely, $M=5.78, S D=.46$. Women reported slightly but significantly higher mean relationship quality $(M=5.85, S D=.49)$ than men $(M=5.72, S D=.43), t_{(105)}=2.39, p$ $<.05$. A multilevel CFA (conducted in Mplus; Bolger \& Laurenceau, 2013) revealed a good internal consistency $(\omega=.79)$ at the within-subjects level. We computed a mean score across the four items for each report.

3 The detachment dimension of the REQ has shown very good reliability both in between- and within-person designs (Feuerhahn, et al., 2014; Sonnentag \& Fritz, 2015) 
Affectionate behaviors toward the partner. In the evening diary, participants were asked how affectionate they behaved toward their partner on a scale from $1=$ not at all, to $6=$ a lot, $M=2.72, S D=1.23$. Men's scores $(M=2.75, S D=1.17)$ did not differ from women's $(M=2.69, S D=1.29), t_{(104)}=.63$, n.s.

\section{Data Analytic Strategy}

To adjust for the multiple sources of dependencies of the data, hypotheses were tested with multilevel structural equation modeling (SEM) using Mplus, version 7.3 (Muthén \& Muthén, 1998-2012). This method has the distinct advantages to allow to a) control for the multiple sources of dependencies, b) test simultaneously the hypothesized relationships between the variables of interest (Bauer, 2003), c) compute a double mediation model, d) directly test the indirect (mediated) effects (Preacher, Zyphur, \& Zhang, 2010), and e) use full information maximum likelihood estimation with robust standard errors (MLR), to take into account deviations from normal distribution (Muthén \& Muthén, 1998-2015). The three levels of distinguishable dyadic diary data were considered as two level of variation, whereby participants' multiple daily diary reports (level 1) were nested within couples (level 2), and a female and male parameter (predictor, mediators, intercept) was computed to distinguish between individuals and allow the computation of actor and partner effect (Bolger \& Laurenceau, 2013; Kenny et al., 2006). To control for autocorrelations, we included the score of the dependent variable (relationship quality) at the previous day. Intercepts were allowed to vary randomly across couples and diaries, and residual terms were allowed to be correlated between partners at levels 1 and 2. We moreover controlled for the interdependence of both partners' predictors and mediators at the within level. Because we were interested in the influence of daily deviation from individual tendencies, all predictors were centered around the individual mean. Hence, the outcome represents the residualized change from the score at the prior day. 
Because we did not have a priori hypothesis regarding gender differences, we explored whether any gender differences occurred, and set equality constraints for parameters of men and women if not significant difference was identified. Except for the intercepts, this was the case for all parameter estimates (Satorra-Bentler Scaled $\chi^{2}$ diff(1) $.006-3.52$ n.s. ${ }^{4}$ ).

\section{Results}

We tested the double mediation model according to which work stress is associated with less detachment from work, which in turn predicts lower affectionate behaviors, and finally lower daily relationship quality in both partners (see Figure 1).

Our model confirmed that stress at work was associated with less detachment at home $(b=-.14, S E=.03, p<.001)^{5}$. Detachment was not significantly associated with affectionate behaviors toward the partner however $(b=-.02, S E=.02, p=.44)$, thus failing to support our hypothesis that failing to detach from work impedes behaving positively toward the partner. Affectionate behaviors, finally, were associated with better daily relationship quality $(b=.19$, $S E=.02, p<.001)$. The direct association between work stress and daily relationship quality remained significant $(b=-.03, S E=.01, p<.01)$, but no significant mediation via the two mediators was found $(b=-.0001, \mathrm{SE}=.001,95 \% \mathrm{CI}=[-.002-.001])$. We controlled for relationship quality at the previous day (autoregressive parameter; $b=.12, S E=.03, p<.01$ ). The standardized coefficients of the model, reflecting the effect sizes, are reported in Figure 3.

We also tested whether work stress affected the partner's daily relationship quality, and whether this association was mediated by own detachment and affectionate behaviors toward the partner. The association between the partner's affectionate behaviors and the own relationship quality was significant $(b=.08, S E=.02, p<.001)$, but participants's stress was not associated with the partner's relationship quality $(b=-.002, S E=.01, p=.85)$, and the two

${ }^{4}$ The size of the partner effect of work-stress on relationship quality differed slightly between men and women $(p=.06)$. But since this was only marginal, and both effects were n.s., we decided to treat them as equal.

${ }^{5}$ In the text, we report the non-standardized coefficient, and in the figures the standardized ones. 
mediators did not significantly mediate this association $(b=.000, S E=.000,95 \% \mathrm{CI}=[-.001$

$-.000])$. The overall model fit was not uniformly satisfactory; $\chi^{2}(37)=70.91, p$-value $<.001$;

$C F I=.92 ; R M S E A=0.03$. The details of the parameters can be found in Table A1 of the

Supplemental Material.

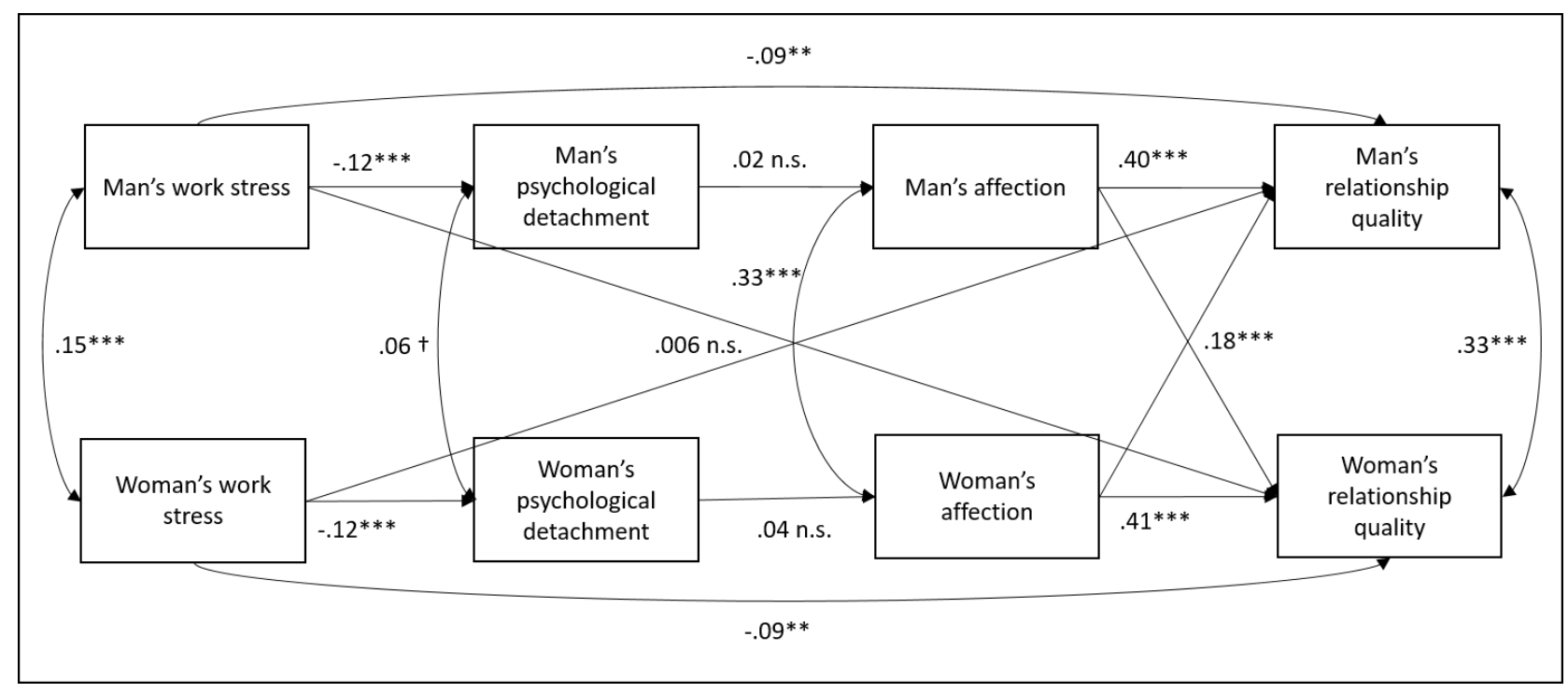

Figure 3: Standardized Results of the Multilevel SEM Double Mediation Model in Study 1.

Note: $\dagger p<.10,{ }^{* *} p<.01, p<.001$, n.s.: non-significant.

\section{Posthoc Analyses}

Our analyses failed to support our double mediation hypothesis according to which work stress leads to lower detachment from work, which in turn leads to lower affection, and finally to lower daily relationship quality. Interestingly, this main reason for the lack of support for this hypothesis is that daily variation in detachment was not predictive of affectionate behaviors in the relationship, contrary to our expectation.

Because the mediating role of detachment in the spill- and crossover process of stress on the relationship was the central aim of this research, we tested a simplified mediation model, removing affection from the original model. We thus tested an actor-partner mediation model of work stress predicting lower daily relationship quality in both partners via less detachment from work. 
The overall model (see Figure 4) presented an excellent fit $\left(\chi^{2}(20)=12.09, p\right.$-value $=$ $.91 ; C F I=1.00 ; R M S E A=0.000)$. It confirmed the postulated association for the actor effect. Work stress predicted lower daily relationship quality $(b=-.04, S E=.01, p<.01)$, and this association was partially mediated by less detachment from work: Participants reported less detachment from work on days when they reported more work stress $(b=-.14, S E=.03, p<$ .001). The less participants detached from work on a given day, the lower they reported on their relationship quality later that day $(b=.04, S E=.01, p<.01)$. The indirect actor effect of work stress on relationship quality via detachment was significant $(b=-.01, S E=.002,95 \%$ $\mathrm{CI}=[-.010--.001])$

Our model also confirmed a partner effect. The more participants detached from work, the higher their partner's relationship quality was on that day $(b=.03, S E=.01, p<.01)$. The indirect partner effect of work stress on relationship quality via detachment was significant $(b$ $=-.004, S E=.002,95 \% \mathrm{CI}=[-.008--.001])$. The details of the parameters can be found in Table A2 of the Supplemental Material.

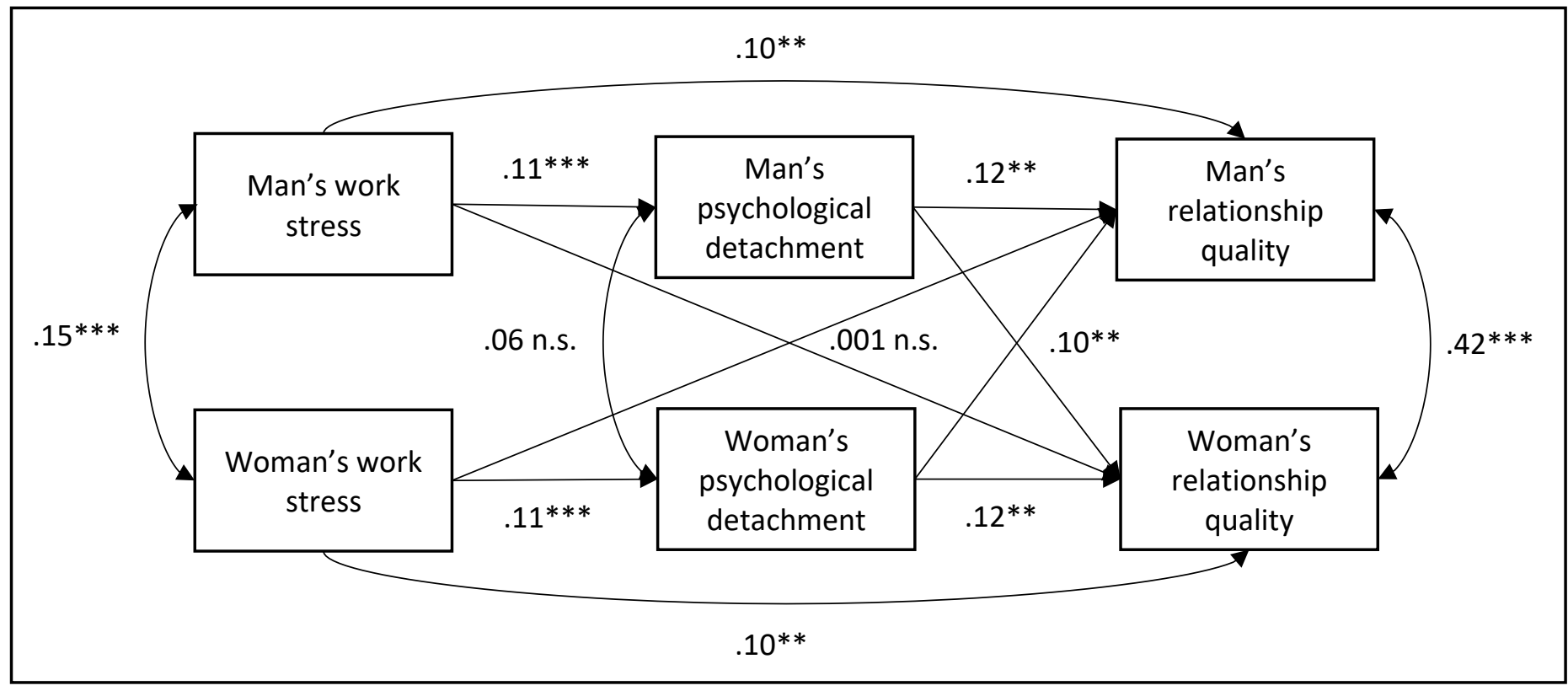

Figure 4: Standardized Results of the Multilevel SEM Simple Mediation Posthoc

Model for Study 1. ${ }^{* *} p<.01,{ }^{* * *} p<.001$, n.s.: non-significant 


\section{Discussion}

To sum-up, in this first study, we had first postulated a processual model whereby work stress would be associated with less detachment, and as a consequence, people would behave less affectionately toward their partner, which would result in both partners feeling less satisfied with their relationship on that day. However, the expected association between detachment and affectionate behaviors was not significant. Thus, we computed a second model without affectionate behaviors, whereby detachment from work would mediate the association between work stress and both partner's relationship satisfaction. This results confirmed this association, showing that detaching from work significantly affects how the couple relationship is evaluated on a specific day.

\section{Study 2}

In our first study, we demonstrated that stress affects daily relationship quality partly because on more stressful days, people detached less, and detachment is associated not only with higher daily relationship quality in the detaching individual, but also in their partner. We next sought to examine whether detachment from work would allow people to benefit more from their interpersonal resources, and thus explain - at least partly - why detachment is associated with better daily individual well-being. Thus, in this second study, we tested the hypothesis that detachment would be negatively associated with evening actor and partner subjective strain, and that this association would occur because partners have more affectionate interactions when they detached more.

\section{Participants and Procedure}

The sample was recruited as part of a larger study investigating spillover and crossover processes in dual-earner parents. Participants learned about the study via advertisements in local newspapers, flyers at pediatrician offices, and through public and 
private organizations in Berlin, Germany. To participate, both partners had to: (a) have at least one preschool-aged child, because these require high child-care investment, (b) have high education levels (university degree, or other vocational training after 13 years of schooling that is considered academic in many countries outside of Germany), and (c) work at least 20 hours per week.

Fifty-six couples agreed to participated and provided complete data. The data of three couples could not be analyzed because there was no situation where both partners were together at home after work (for more details, see Klumb et al., 2016). The final sample consisted of 53 dual-earner couples. Participants were aged between 25 and 46 years $(M=37$ years, $S D=4.58)$. Most participants were married $(85 \%)$; the remainder were cohabiting. The mean relationship duration was 8.9 years $(S D=4.04)$. Given the eligibility criteria, (a) participants had between one and four preschool-aged children $(M=1.74, S D=.65)$ with an average age of 4.5 years $(S D=2.2)$, and (b) $98 \%$ held a university degree, while $2 \%$ had received other high-level vocational training. Men reported an average of 41.79 hours of paid work per week $(S D=9.24, \min .=16, \max .=65)$, and women 34.62 hours $(S D=8.42, \min .=$ 15, $\max .=53)$. Most participants were employees $(93 \%$; the remainder were self-employed) and more than half (58.7\%) held a leadership position (leadership span between 1 and 50 collaborators). Half of the participants were occupied full-time (two thirds of the men and one third of the women) and of those, fifty percent earned more than $€ 30,600$ (about $\$ 34,733$ USD) of gross yearly income.

At an initial measurement occasion, participants completed an online questionnaire assessing socio-demographic characteristics. Four months later, they participated in a sevenday experience-sampling phase, beginning with an in-home training session held by a research assistant. During this session, an overview of the study was provided and the use of the experience-sampling materials implemented on a handheld computer (Psion 3a, Psion 
PLC, London, Great Britain) was explained. During the seven work day experience-sampling period, both partners simultaneously received five prompts to complete a questionnaire on the device. They were prompted approximately every 2.5-3 hours, between 9:00 a.m. and 9:30 p.m. In addition, they completed a diary questionnaire after waking up and before going to bed (total of seven measurement occasions per day). The diary questionnaires assessed momentary affect (with the Multidimensional Affect Questionnaire, MDBF; Steyer, Schwenkmezger, Notz, \& Eid, 1997), situational variables (e.g. location), and an extended version of the Rochester Interaction Record (RIR; Reis \& Wheeler, 1991) to evaluate social interactions that occurred since the last measurement occasion (both face-to-face and electronically mediated contacts such as phone calls, e-mail, texts messages, etc.). Participants answered to $91.1 \%$ of the reports, and the vast majority (68\%) finished less than 10 minutes after the prompting signal. Participants did not receive monetary compensation but took part in a lottery to win a weekend in a hotel, including dinner and child care. The study procedure was approved by the local institutional ethics review board.

\section{Daily Diary Measures}

Detachment from work. A single item asked participants to indicate on a five-point scale $(1=$ not at all, to $5=a$ lot $)$ how much they could distance themselves from work related contents since the last measurement occasion. This is an item of the REQ that has shown to measure detachment reliably (Sonnentag \& Fritz, 2007). This item was only presented when participants had left their workplace. The mean detachment was $4.12(S D=.78)$, and did not differ between men $(M=4.10, S D=.75)$ and women $(M=4.84, S D=.82), t_{(52)}=.259$, n.s.

Affectionate couple interactions. When participants experienced interactions that were either longer than 10 minutes or otherwise meaningful, questions from the RIR (Reis $\&$ Wheeler, 1991) about the quality of each of these interactions were triggered. When both partners were at home and had such an interaction together, they indicated whether this 
interaction was affectionate $(0=n o, 1=y e s)$. The mean number of interactions with the partner since the last measurement occasion (time-lag of about 2.5-3 hours) was .64 for men and .66 for women $(S D=.30, \min =0, \max =2$ for both groups $)$. On average, men reported $.29(S D=.28)$ and women .31 affectionate couple interactions $(S D=.33)$, and did not differ significantly, $t_{(52)}=-.536$, n.s.

Evening strain. To operationalize strain level, the tense arousal dimension of the MDBF (Steyer et al., 1997) was used. When at home after work, participants indicated their current affective state along two unipolar items (agitated and relaxed) ranging from $1=$ not at all to $5=$ a lot. We reverse coded the relaxed item and used the composite of the two items at each occasion. Moreover, in the analyses, we controlled for the strain level at the previous assessment point, which sometimes related to an assessment at work. Men's and women's mean tense arousal were both $2.26(S D=.40$ and .52 , respectively).

\section{Data Analytic Strategy}

As in Study 1, we analyzed the data means of a Multilevel SEM with random intercepts. To consider autocorrelations of the outcome variable tense arousal, we included the score of the previous measurement occasion. Since none of the parameter estimates differed significantly across gender, $\chi^{2}$ diff(13) $=14.37$, n.s., we used a gender constrained model.

\section{Results}

\section{Mediation of the association between detachment and strain by affectionate}

interactions. Our second hypothesis was that detachment would be negatively associated with own and partner evening strain because partners have more affectionate interactions when they detach more from work.

Our model (see Figure 5) confirmed the hypothesis that detachment was associated with more affectionate interactions $(b=.05, S E=.01, p<.001)$ which in turn was linked to 
less individual evening strain $(b=-.25, S E=.08, p<.001)$. The total effect from detachment to evening strain was composed of a significant direct association between detachment and evening strain $(b=-.12, S E=.03, p<.001)$ as well as of an indirect effect via affectionate interactions $(b=-.01, S E=.01, p<.05)$. The hypothesized partner effects were not confirmed in this model: neither a significant association was found between detachment and the partner's evening strain, nor one between partner's perception of affection in the interaction and focal person's evening strain. Additionally, previous strain predicted less detachment $(b=$ $-.29, S E=.06, p<.001)$, consistent with the result of Model 1 showing that work stress is associated with lower detachment. The model fit was very satisfactory: $\chi^{2}(29)=34.938, p$ value $=.24 ; C F I=0.97 ; R M S E A=0.02$. The details of the parameters can be found in Table A3 of the Supplemental Material.

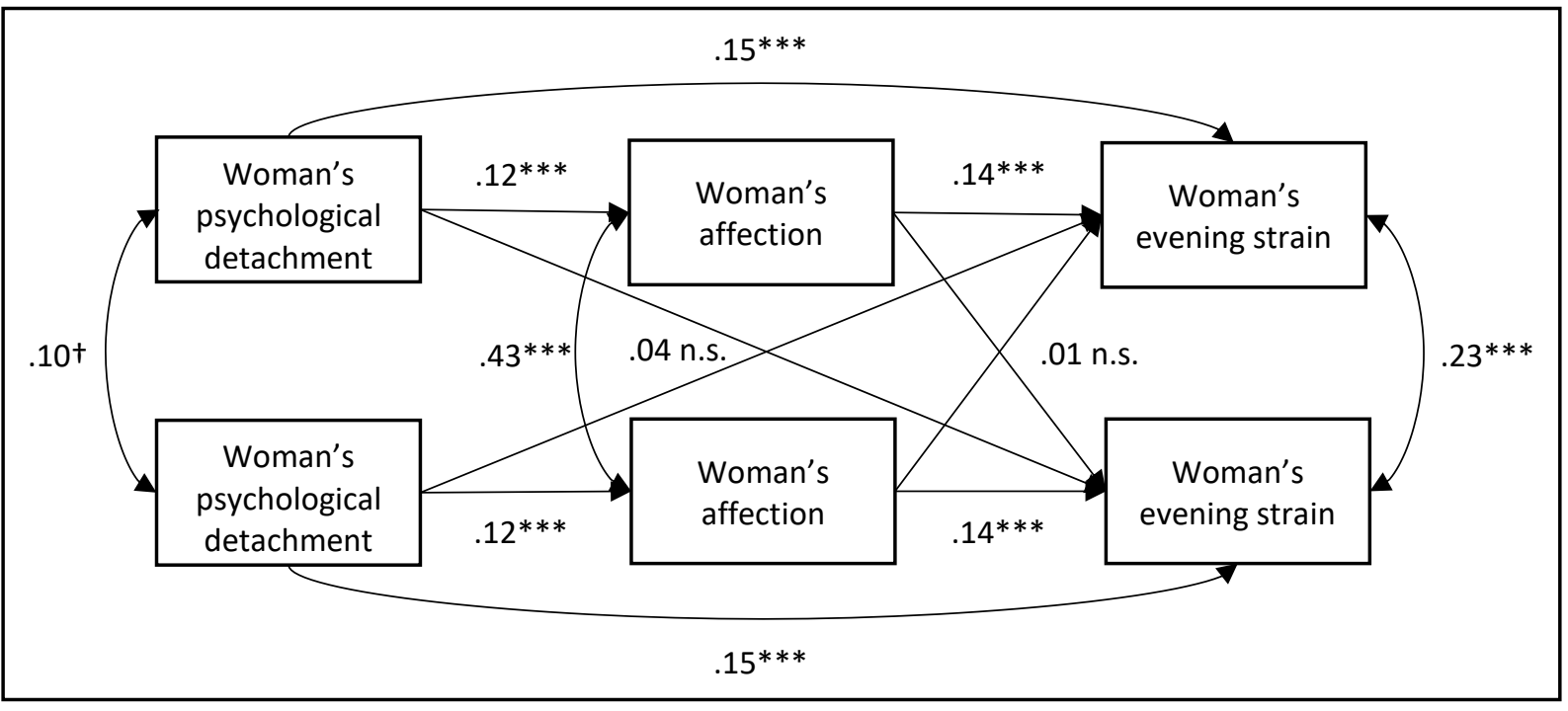

Figure 5: Standardized Results of the Multilevel SEM Simple Mediation Model for Study 2. Note: $\dagger p<.10,{ }^{* * *} p<.001$, n.s.: non-significant. 


\section{Discussion}

In this second study with dual-earner couples, we predicted that detaching from work would increase the possibility of experiencing higher quality interactions, and that this could explain why detachment affects the actor and the partner's individual well-being. The results supported this hypothesis, however only for the actor. When lacking detachment, people experienced less affection when interacting with their partner, and this was associated with higher evening strain. Our prediction that individual strain would also be diminished by the partner's detachment was not supported. Study 1 showed a crossover effect on relationship satisfaction, but people seem to be able to maintain their individual well-being level when their partners lacks detachment. It should be kept in mind, however, that the sample size of Study 2 was smaller and perhaps did not provide sufficient power to detect a partner effect, as those are typically smaller in size (Kenny \& Malloy, 1988). Further research should investigate with a larger sample whether detachment affects the partner's daily well-being.

\section{General Discussion}

This set of results is to our knowledge the first to demonstrate the presence of meaningful daily consequences of detachment from work on relationship quality and to indicate the importance of the quality of interpersonal interactions in how detachment affects personal well-being. Study 1 demonstrated that daily work stress affects evening relationship quality, and that this association is partly explained by people detaching less from their work. However, our double mediation model according to which affectionate behavior would additionally mediate the association between detachment and relationship quality was not supported by the data. Affection however did play a significant role in our second study, as it was shown to partly mediate the now well-known association between detachment and individual strain (see Sonnentag \& Fritz, 2015). 
All the investigated paths of our studies were equivalent across gender. This is in line with a recent meta-analysis on work-family conflict showing no gender differences (Nohe et al., 2015) and more generally with the literature showing that gender similarities exceed differences, especially within close-relationship processes (MacGeorge, Graves, Feng, Gillihan, \& Burleson, 2004). However, to our knowledge, gender differences have not been systematically investigated in the detachment literature (see Sonnentag \& Fritz, 2015).

\section{Detachment Explains How Stress Affects Relationship Quality (but not Affection)}

We had postulated a processual model whereby stress would decrease detachment from work at home. The lack of detachment would then have predicted more positive (affectionate) behaviors toward the partner, which in turn, would have been associated with higher daily relationship quality. The results only partly supported this hypothesis. Indeed, in our double mediation model (see Figures 1 and 3), detaching more from work was not, as predicted, associated with more affectionate behaviors toward the partner, and the mediational path did not reach significance. It thus seems like keeping occupied with work-related content does not affect how affectionate individuals behave toward their partner. This is surprising given that previous research indicated that lacking detachment makes partners less available for the relationship, and depletes self-control (Danner-Vlaardingerbroek et al., 2013; DannerVlaardingerbroek, Kluwer, van Steenbergen, \& van der Lippe, 2016). A possibility for this lack of an effect might be the too high multicollinearity due to the high association between affection and relationship quality, explaining the low model fit. It might also be that other processes better explain how low detachment affects relationship quality, that should be explored in further research.

Nevertheless, when we removed affection from the model, we found that detachment significantly mediates the association between work stress and not only daily own relationship quality but also the romantic partner's one. Thus, when being cognitively occupied with 
work-related content at home, people not only experience less individual well-being, as has been shown in numerous previous research (for a review, see Sonnentag \& Fritz, 2015), but also lower relational well-being. As per the Stress-Divorce Model (Randall \& Bodenmann, 2009), stress might affect the relationship because partners spend less time together, resulting in alienation. Nevertheless, as in the mother-child relationship, whereby the quality of the interactions is not compromised by the quantity of the time spent together (Booth, ClarkeStewart, Vandell, McCartney, \& Owen, 2002), our results show that the quality of the time romantic partners spend together matters. When absorbed by their work while being together, the perception of the relationship by both partners is compromised. Though the associations are small- to medium-sized, over time, these hindrances to daily relationship quality likely accumulate and threaten the overall relationship's quality and longevity (Neff \& Karney, 2004).

According to the perseverative-cognition hypothesis, stressors affect health mainly because of the cognitions they trigger, which prolong stress-related affective and physiological activation (Brosschot et al., 2006). Hence, failing to detach from work may leave less resources for self-regulation and thus intensify reactions to negative relationship events. In fact, coping with stress largely depletes energetic resources and this, in turn, affects daily relationship interactions (Unger et al., 2017) and satisfaction (Buck and Neff, 2012), resulting in partners' relationship satisfaction being more reactive to couple interactions (e.g. support or conflict; Neff \& Karney, 2009).

Interestingly, detachment not only predicted the own relationship quality, but partner's relationship quality was significantly affected, too. A plausible explanation is that when partners detach less, they are perceived as less available. In fact, Danner-Vlaardingerbroek et al. (2013) showed that when people bring residual work stress home, their partners perceive them as less available, yielding in less positive and more negative marital behaviors. 


\section{Affection Mediates the Association between Detachment and Individual Strain}

In line with previous research on detachment (Demerouti et al., 2012; Feuerhahn et al., 2014), our results show that detachment is associated with lower evening strain; when more occupied with work-related content, people feel more agitated and less calm. We moreover demonstrated that, in individuals cohabiting with their partner, this effect is partially accounted for by increased experience of affection when they detach more. Thus, when people are less engaged with their jobs at home, they are likely more available for sharing affection (Danner-Vlaardingerbroek et al., 2013) and thus feel better. As recently shown by Unger and colleagues (2017), work stress depletes self-regulatory resources, which in turn predicts more negative and less positive interactions with the partner. Positive interactions are an important mechanism to diminish the negative effect of stress on individual well-being (i.e., Debrot, Schoebi, Perrez, \& Horn, 2014; Ditzen et al., 2008; Floyd, 2008). Thus, in line with a recent review underlining the importance of the quality of marital interactions for crossover processes in romantic relationships (Steiner \& Krings, 2016), the results of the present study show that when detaching from work at home, people seem to benefit more from the resources that close relationships offer (Hobfoll, 1989).

\section{Limitations and Future Research}

The correlational nature of our analyses do not allow to draw firm causal conclusions and reverse causation is a possibility. For example, people might keep more occupied with their work as a way of avoiding a less satisfying relationship; or evening strain might cause people to perceive less affection (Neff \& Karney, 2009). However, our daily diary design affords some validity that the present processes unfold in the hypothesized temporal sequences. This is not only supported by the temporal sequence of the events, for example, work stress occurred before the investigated couple processes at home, but also because we controlled for the outcome at the previous session, thus excluding that the effects are driven 
by the people already feeling satisfied or strained (Conner \& Lehman, 2012). Another potential methodological limitation is that participants did not complete all the reports. However, the missing rate was low ( $~ 8 \%$ in both studies) and there is no reason to expect this not to be random (Bolger \& Laurenceau, 2013).

The nature of the work-related thoughts or behaviors was not assessed. Previous research has shown that the valence of thoughts content differentially affects individual wellbeing. Whereas work-related rumination or worries negatively affects actor and partner strain (Querstret \& Cropley, 2012; Slatcher, Robles, Repetti, \& Fellows, 2010), positively reflecting about ones' job is beneficial for well-being (Meier, Cho, \& Dumani, 2015). Further research should investigate whether the different nature of the content also differentially affects the partner or relational well-being. A beneficial effect of positive reflection could be expected, as capitalization (i.e. sharing positive events) improves relational well-being (Gable, Reis, \& Mark, 2010). Overall however, our results indicate a general harmful influence of lack of detachment on perceived relationships quality.

We did not assess detailed information about the kind of stress that was experienced at work. Depending on their nature, stressors can have different consequences on strain (e.g. Lepine, Podsakoff \& Lepine, 2005). Thus, different work stressors might differentially affect detachment. Moreover, stress can also increase affiliative behavior (Taylor, 2006). Hence, stress might result in differential interpersonal consequences. Because job and marital satisfaction are linked (Rogers \& May, 2003), it would be interesting to investigate whether job satisfaction moderates the impact of detachment on relationship satisfaction, such that lack of detachment would be expected to be mostly detrimental in case of low job satisfaction. Another interesting line of inquiry is whether different kind of interactions with the partner could serve as facilitator of detachment. Positive activities can help buffer the impact of stress (Iwasaki, 2006) and promote detachment (Feuerhahn et al., 2014). Moreover, sharing 
positive activities with the partner may help to maintain a regular detachment practice (Aron, Norman, Aron, McKenna, \& Heyman, 2000), by combining the positive effects of activities, and being with another person, which might distract from job related thought. Indeed, positive relational processes can buffer the negative impact of stress (Cohen \& Pressman, 2004). A recent study showed that partner support on weekends was associated with recipient's recovery and this, in turn, increased work-engagement during the week (Park \& Haun, 2016). Additionally, touching and being touched by one's partner has been shown to buffer the negative effects of trying to suppress one's thoughts, a coping style that favors rumination (Debrot et al., 2014; Wenzlaff \& Luxton, 2003). Therefore, sharing physical affection might facilitate detachment.

\section{Conclusion}

The life of dual-earner parents may often be challenging; the demands associated with the work and family contexts are multiple and might conflict with one another (Nohe et al., 2015), thereby threatening the maintenance of well-being of this increasing population. The present study shows that, amid their daily events, detachment affects the individual experiencing stress at work and in addition, the couple's satisfaction in daily life. Moreover, detachment was shown to affect the perception of the interaction with the partner and via this path contributes to individual well-being. This phenomenon may become increasingly important as the growing use of technology allows people to connect with their jobs everywhere at any time, lowering the likelihood of detaching from work (Richardson \& Thompson, 2012). The current studies emphasize the importance of considering the interpersonal consequences of detachment. 


\section{References}

Allen, T. D., Cho, E., \& Meier, L. L. (2014). Work-family boundary dynamics. Annual Review of Organizational Psychology and Organizational Behavior, 1(1), 99-121. doi:10.1146/annurev-orgpsych-031413-091330

American Psychological Association. (2016). 2016 Work and well-being survey. Retrieved from https://apa.org/news/press/releases/phwa/index.aspx

Aron, A., Norman, C. C., Aron, E. N., McKenna, C., \& Heyman, R. E. (2000). Couples' shared participation in novel and arousing activities and experienced relationship quality. Journal of Personality and Social Psychology, 78, 273-284.

Bakker, A. B., \& Demerouti, E. (2013). The Spillover-Crossover model. In J. G. Grzywacz \& E. Demerouti (Eds.), New frontiers in work and family research (pp. 54-70). New York: Psychology Press.

Bauer, D. J. (2003). Estimating multilevel linear models as structural equation models. Journal of Educational and Behavioral Statistics, 28, 135-167. doi:10.3102/10769986028002135

Bolger, N., \& Laurenceau, J.-P. (2013). Intensive longitudinal methods: An introduction to diary and experience sampling research. New York: Guilford Press.

Booth, C. L., Clarke-Stewart, K. A., Vandell, D. L., McCartney, K., \& Owen, M. T. (2002). Child-care usage and mother-infant "quality time". Journal of Marriage and Family, 64, 16-26. doi:10.1111/j.1741-3737.2002.00016.x

Buck, A. A., \& Neff, L. A. (2012). Stress spillover in early marriage: The role of selfregulatory depletion. Journal of Family Psychology, 26, 698-708. doi:10.1037/a0029260 
Carnes, A. M. (2017). Bringing work stress home: The impact of role conflict and role overload on spousal marital satisfaction. Journal of Occupational and Organizational Psychology, 90, 153-176. doi:10.1111/joop.12163

Cobb, R. J., Davila, J., \& Bradbury, T. N. (2001). Attachment security and marital satisfaction: The role of positive perceptions and social support. Personality and Social Psychology Bulletin, 27, 1131-1143. doi:10.1177/0146167201279006

Cohen, S., \& Pressman, S. (2004). The stress-buffering hypothesis. In N. B. Anderson (Ed.), Encyclopedia of health and behavior (pp. 780-782). Thousand Oaks: Sage Publications.

Conner, T. S., \& Lehman, B. J. (2012). Getting started: Launching a study in daily life. In M. R. Mehl \& T. S. Conner (Eds.), Handbook of research methods for studying daily life (pp. 89-107). New York: Guilford Press.

Danner-Vlaardingerbroek, G., Kluwer, E. S., van Steenbergen, E. F., \& van der Lippe, T. (2013). Knock, knock, anybody home? Psychological availability as link between work and relationship. Personal Relationships, 20, 52-68. doi:10.1111/j.1475-

6811.2012.01396.x

Danner-Vlaardingerbroek, G., Kluwer, E. S., van Steenbergen, E. F., \& van der Lippe, T. (2016). How work spills over into the relationship: Self-control matters. Personal Relationships, 23(3), 441-455. doi:10.1111/pere.12136

Debrot, A., Schoebi, D., Perrez, M., \& Horn, A. B. (2013). Touch as an interpersonal emotion regulation process in couples' daily lives: The mediating role of psychological intimacy. Personality and Social Psychology Bulletin, 39, 1373-1385. doi:10.1177/0146167213497592

Debrot, A., Schoebi, D., Perrez, M., \& Horn, A. B. (2014). Stroking your beloved one's white bear: Responsive touch by the romantic partner buffers the negative effect of thought 
suppression on daily mood. Journal of Social and Clinical Psychology, 33, 75-97. doi:10.1521/jscp.2014.33.1.75

Debrot, A., Meuwly, N., Muise, A., Impett, E. A., \& Schoebi, D. (2017). More than just sex: Affection mediates the association between sexual activity and well-being. Personality and Social Psychology Bulletin, 43, 287-299. doi:10.1177/0146167216684124

Demerouti, E., Bakker, A. B., Sonnentag, S., \& Fullagar, C. J. (2012). Work-related flow and energy at work and at home: A study on the role of daily recovery. Journal of Organizational Behavior, 33, 276-295. doi:10.1002/job.760

Demsky, C. A., Ellis, A. M., \& Fritz, C. (2014). Shrugging it off: Does psychological detachment from work mediate the relationship between workplace aggression and workfamily conflict? Journal of Occupational Health Psychology, 19, 195-205. doi:10.1037/a0035448

Eurofound. (2015). First findings: Sixth European working conditions survey. Sixth European working conditions survey: 15,68 EN. Luxembourg: Publications Office.

Ditzen, B., Hoppmann, C., \& Klumb, P. (2008). Positive couple interactions and daily cortisol: On the stress-protecting role of intimacy. Psychosomatic Medicine, 70, 883-889.

Feuerhahn, N., Sonnentag, S., \& Woll, A. (2014). Exercise after work, psychological mediators, and affect: A day-level study. European Journal of Work and Organizational Psychology, 23(1), 62-79. doi:10.1080/1359432X.2012.709965

Floyd, K. (2008). Communicating affection: Interpersonal behavior and social context. Cambridge: Cambridge University Press.

Floyd, K., Hess, J. A., Miczo, L. A., Halone, K. K., Mikkelson, A. C., \& Tusing, K. J. (2005). Human affection exchange: VIII. Further evidence of the benefits of expressed affection. Com4munication Quarterly, 53(3), 285-303. doi:10.1080/01463370500101071 
Floyd, K., \& Riforgiate, S. (2008). Affectionate communication received from spouses predicts stress hormone levels in healthy adults. Communication Monographs, 75(4), 351368. doi:10.1080/03637750802512371

Gable, S. L., Reis, H. T., \& Mark, P. Z. (2010). Good news! Capitalizing on positive events in an interpersonal context. In M. Zanna (Ed.), Advances in experimental social psychology (pp. 195-257). New York: Elsevier Press.

Gottman, J. M., \& Notarius, C. I. (2000). Decade review: Observing marital interaction. Journal of Marriage and Family, 62, 927-947.

Hahn, V. C., \& Dormann, C. (2013). The role of partners and children for employees' psychological detachment from work and well-being. Journal of Applied Psychology, 98, 26-36. doi:10.1037/a0030650

Hobfoll, S. E. (1989). Conservation of resources: A new attempt at conceptualizing stress. American Psychologist, 44(3), 513-524. doi:10.1037/0003-066X.44.3.513

Hobfoll, S. E. (2002). Social and psychological resources and adaptation. Review of General Psychology, 6(4), 307-324. doi: 10.1037/1089-2680.6.4.307

Iwasaki, Y. (2006). Counteracting stress through leisure coping: A prospective health study. Psychology, Health and Medicine, 11, 209-220. doi:10.1080/13548500500155941

Kenny, D. A. (2015). Multiple Regression. Retrieved from http://davidakenny.net/cm/mr.htm\#MC

Kenny, D. A., Kashy, D. A., \& Cook, W. L. (2006). Dyadic data analysis. New York: Guilford Press.

Kenny, D. A., \& Malloy, T. E. (1988). Partner effects in social interaction. Journal of Nonverbal Behavior, 12, 34-57. doi: 10.1007/BF00987351 
Klumb, P. L., Voelkle, M. C., \& Siegler, S. (2016). How negative social interactions at work seep into the home: A prosocial and an antisocial pathway. Journal of Organizational Behavior, 5(3), 354. doi:10.1002/job.2154

Lavner, J. A., \& Clark, M. A. (2017). Workload and marital satisfaction over time: Testing lagged spillover and crossover effects during the newlywed years. Journal of Vocational Behavior. Advance online publication. doi: 10.1016/j.jvb.2017.05.002

Lavner, J. A., Karney, B. R., \& Bradbury, T. N. (2016). Does couples' communication predict marital satisfaction, or does marital satisfaction predict communication? Journal of Marriage and Family, 78(3), 680-694. doi:10.1111/jomf.12301

Lepine, J. A., Podsakoff, N. P., \& Lepine, M. A. (2005). A meta-analytic test of the challenge stressor--hindrance stressor framework: An explanation for inconsistent relationships among stressors and performance. Academy of Management Journal, 48(5), 764-775. doi:10.5465/AMJ.2005.18803921

MacGeorge, E. L., Graves, A. R., Feng, B., Gillihan, S. J., \& Burleson, B. R. (2004). The myth of gender cultures: Similarities outweigh differences in men's and women's provision of and responses to supportive communication. Sex Roles, 50, 143-175.

Meier, L. L., Cho, E., \& Dumani, S. (2015). The effect of positive work reflection during leisure time on affective well-being: Results from three diary studies. Journal of Organizational Behavior, 255-278. doi:10.1002/job.2039

Meier, L. L., \& Cho, E. (2016). Lack of psychological detachment as linking mechanism between job demands and social undermining at home: Results from three studies. Manuscript submitted for publication.

Muthén, L. K., \& Muthén, B. O. (1998-2012). Mplus User's Guide (Seventh Edition). Los Angeles, CA: Muthén \& Muthén. 
Neff, L. A., \& Karney, B. R. (2004). How does context affect intimate relationships? Linking external stress and cognitive processes within marriage. Personality and Social Psychology Bulletin, 30, 134-148. doi:10.1177/0146167203255984

Neff, L. A., \& Karney, B. R. (2007). Stress crossover in newlywed marriage: A longitudinal and dyadic perspective. Journal of Marriage and Family, 69, 594-607. doi:10.1111/j.1741-3737.2007.00394.x

Neff, L. A., \& Karney, B. R. (2009). Stress and reactivity to daily relationship experiences: How stress hinders adaptive processes in marriage. Journal of Personality and Social Psychology, 97, 435-450. doi:10.1037/a0015663

Nohe, C., Meier, L. L., Sonntag, K., \& Michel, A. (2015). The chicken or the egg? A metaanalysis of panel studies of the relationship between work-family conflict and strain. Journal of Applied Psychology, 100, 522-536. doi:10.1037/a0038012

Park, Y., \& Haun, V. C. (2016). Dual-earner couples' weekend recovery support, state of recovery, and work engagement: Work-linked relationship as a moderator. Journal of Occupational Health Psychology. doi:10.1037/ocp0000045

Preacher, K. J., \& Selig, J. P. (2012). Advantages of Monte Carlo confidence intervals for indirect effects. Communication Methods and Measures, 6, 77-98. doi:10.1080/19312458.2012.679848

Preacher, K. J., Zyphur, M. J., \& Zhang, Z. (2010). A general multilevel SEM framework for assessing multilevel mediation. Psychological Methods, 15, 209-233. doi: $10.1037 / \mathrm{a} 0020141$

Querstret, D., \& Cropley, M. (2012). Exploring the relationship between work-related rumination, sleep quality, and work-related fatigue. Journal of Occupational Health Psychology, 17, 341-353. doi:10.1037/a0028552 
Randall, A. K., \& Bodenmann, G. (2009). The role of stress on close relationships and marital satisfaction. Clinical Psychology Review, 29, 105-115. doi:10.1016/j.cpr.2008.10.004

Reis, H. T. (2012). Why researchers should think "real-world": A conceptual rationale. In M. R. Mehl \& T. S. Conner (Eds.), Handbook of research methods for studying daily life (pp. 3-21). New York: Guilford Press.

Reis, H. T., \& Wheeler, L. (1991). Studying social interaction with the Rochester Interaction Record. In M. P. Zanna (Ed.), Advances in experimental social psychology: Vol. 24 (pp. 269-318). San Diego: Academic Press.

Repetti, R. L., \& Wood, J. (1997). Effects of daily stress at work on mothers' interactions with preschoolers. Journal of Family Psychology, 11, 90-108.

Richardson, K. M., \& Thompson, C. A. (2012). High tech tethers and work-family conflict: A conservation of resources approach. Engineering Management Research, 1. doi: 10.5539/emr.v1n1p29

Robles, T. F., Slatcher, R. B., Trombello, J. M., \& McGinn, M. M. (2014). Marital quality and health: A meta-analytic review. Psychological Bulletin, 140, 140-187. doi: $10.1037 / \mathrm{a} 0031859$

Rogers, S. J., \& May, D. C. (2003). Spillover between marital quality and job satisfaction: Long-term patterns and gender differences. Journal of Marriage and Family, 65, 482-495. doi:10.1111/j.1741-3737.2003.00482.x

Schimmack, U., \& Rainer, R. (2002). Experiencing activation: Energetic arousal and tense arousal are not mixtures of valence and activation. Emotion, 2, 412-417. doi:10.1037/1528-3542.2.4.412

Schoebi, D., Perrez, M., \& Bradbury, T. N. (2012). Expectancy effects on marital interaction: Rejection sensitivity as a critical moderator. Journal of Family Psychology, 26, 709-718. doi:10.1037/a0029444 
Schulz, M. S., Cowan, P. A., Pape Cowan, C., \& Brennan, R. T. (2004). Coming home upset: Gender, marital satisfaction, and the daily spillover of workday experience into couple interactions. Journal of Family Psychology, 18, 250-263. doi:10.1037/0893-3200.18.1.250

Schwarz, N. (2012). Why researches should think "real-time": A cognitive rationale. In M. R. Mehl \& T. S. Conner (Eds.), Handbook of research methods for studying daily life (pp. 2242). New York: Guilford Press.

Slatcher, R. B., Robles, T. F., Repetti, R. L., \& Fellows, M. D. (2010). Momentary work worries, marital disclosure, and salivary cortisol among parents of young children. Psychosomatic Medicine, 72, 887-896. doi:10.1097/PSY.0b013e3181f60fcc

Sonnentag, S. (2011). Recovery from fatigue: The role of psychological detachment. In P. L. Ackerman (Ed.), Cognitive fatigue: Multidisciplinary perspectives on current research and future applications (pp. 253-272). Washington: American Psychological Association.

Sonnentag, S., \& Bayer, U.-V. (2005). Switching off mentally: Predictors and consequences of psychological detachment from work during off-job time. Journal of Occupational Health Psychology, 10, 393-414. doi: 10.1037/1076-8998.10.4.393

Sonnentag, S., \& Fritz, C. (2015). Recovery from job stress: The stressor-detachment model as an integrative framework. Journal of Organizational Behavior, 36(S1), S72-S103. doi: 10.1002/job.1924

Steiner, R. S., \& Krings, F. (2016). How was your day, darling? A literature review of positive and negative crossover at the work-family interface in couples. European Psychologist, 21, 296-315. doi: 10.1027/1016-9040/a000275

Steyer, R., Schwenkmezger, P., Notz, P., \& Eid, M. (1997). Der mehrdimensionale Befindlichkeitsfragebogen (MDBF). Handanweisung [The multidimensional affect rating scale (MDBF). Manual]. Göttingen: Hogrefe. 
Taylor, S. E. (2006). Tend and befriend: Biobehavioral bases of affiliation under stress. Current Directions in Psychological Science, 15, 273-277. doi: 10.1111/j.14678721.2006.00451.x

ten Brummelhuis, L. L., \& Bakker, A. B. (2012). Staying engaged during the week: The effect of off-job activities on next day work engagement. Journal of Occupational Health Psychology, 17, 445-455. doi:10.1037/a0029213

Timmons, A. C., Arbel, R., \& Margolin, G. (2017). Daily patterns of stress and conflict in couples: Associations with marital aggression and family-of-origin aggression. Journal of Family Psychology, 31(1), 93-104. doi: 10.1037/fam0000227

Unger, D., Sonnentag, S., Niessen, C., \& Kuonath, A. (2017). Love won’t tear us apart but work might: How job stressors relate to constructive and destructive reactions to one's romantic partner's negative behavior. International Journal of Stress Management, 24 (Suppl 1), 74-97. doi:10.1037/str0000034

Wang, S.-W., \& Repetti, R. L. (2012). After the workday ends: How jobs impact family relationships. In A. L. Vangelisti (Ed.), Routledge handbook of family communication (2nd ed., pp. 409-423). New York, NY: Routledge.

Wendsche, J., \& Lohmann-Haislah, A. (2016). A meta-analysis on antecedents and outcomes of detachment from work. Frontiers in Psychology, 7, 2072. doi: 10.3389/fpsyg.2016.02072

Wenzlaff, R. M., \& Luxton, D. D. (2003). The role of thought suppression in depressive rumination. Cognitive Therapy and Research, 27, 293-308. doi: 10.1023/A:1023966400540

Westman, M., Vinokur, A. D., Hamilton, V. L., \& Roziner, I. (2004). Crossover of marital dissatisfaction during military downsizing among Russian army officers and their spouses. Journal of Applied Psychology, 89, 769-779. doi: 10.1037/0021-9010.89.5.769 